\title{
INSTRUMENTOS DE POLÍTICAS PÚBLICAS EM GESTÃO AMBIENTAL E SUSTENTABILIDADE NO BRASIL
}

\author{
Carmino Hayashi ${ }^{1}$ \\ Leonardo Henrique de Almeida e Silva²
}

\begin{abstract}
RESUMO
Este trabalho representa uma síntese sobre os instrumentos de políticas públicas em Gestão Ambiental e Sustentabilidade no Brasil. Os objetivos fundamentaram-se na identificação, descrição, análise e avaliação crítica sobre os principais instrumentos de políticas públicas em vigência, precedidos por um breve histórico sobre a evolução das mesmas. Em termos metodológicos foram levantados dados bibliográficos pertinentes ao histórico, órgãos, legislações, instrumentos e estratégias aplicadas em políticas públicas, com ênfase aos aspectos relacionados à Política Nacional do Meio Ambiente. Referencialmente estas políticas públicas seguem as normativas da Constituição da República Federativa do Brasil de 1988 e do Ministério do Meio Ambiente que agregam o Sistema Nacional do Meio Ambiente e o Conselho Nacional do Meio Ambiente, além do Instituto Nacional do Meio Ambiente e dos Recursos Naturais Renováveis, e da Lei Federal no 6.938/81 que dispõe sobre a Política Nacional do Meio Ambiente. Na iniciativa privada contamos ainda com as políticas ambientais formuladas pela Organização Internacional para Padronização e pela Organização Mundial de Comércio, como principais instrumentos destas políticas ambientais. Cabe a estes instrumentos a condução e cumprimento das estratégias econômicas e preservação dos recursos ambientais. Concluímos que do ponto de vista de legislação os princípios, estratégias e instrumentos necessários para uma eficiente gestão ambiental já se encontram disponíveis, entretanto necessitam de melhor aprimoramento, principalmente em relação a uma gestão pública mais efetiva em suas aplicações e fiscalizações de acordo com as normas e legislações vigentes.
\end{abstract}

PALAVRAS CHAVE: Gestão ambiental, Sustentabilidade, Políticas públicas ambientais, Meio ambiente.

\section{PUBLIC POLICY INSTRUMENTS IN ENVIRONMENTAL MANAGEMENT AND SUSTAINABILITY IN BRAZIL}

\section{SUMMARY}

This paper is an overview of the instruments of public policies in Environmental Management and Sustainability in Brazil. The objectives are substantiated on the identification, description, analysis and critical review of the main instruments of public policies in force, preceded by a brief history of their evolution. In terms of methodology were raised relevant bibliographic data to the historical, organs, legislation, instruments and strategies applied in public policy, with emphasis on aspects related to the National Environmental Policy. Referentially these public policies follows the norms of the Constitution of the Federative Republic of Brazil of 1988 and the Ministry of Environment that aggregates the National Environmental System and the National Environmental Council, in addition to the National Institute of Environment and Renewable Natural Resources and the Federal Law No. 6,938/81 which

\footnotetext{
${ }^{1}$ Graduação em Ciências Biológicas/USP-RP, Bacharel em Administração Pública/UFSJ e Doutor em Ciências (Ecologia e Recursos Naturais) - UFSCar, E-mail: hayashi@terra.com.br

${ }_{2}^{2}$ Professor do IPTAN, Professor do IF/ Câmpus São João del-Rei, Graduação em Administração/FCCAMS, Graduação em Ciências Econômicas/UFJF e Mestre em Economia/UFES, E-mail: leonardo.henrique@ifsudestemg.edu.br
} 


\section{Periódica Eletrônica

rules on National Environmental Policy. In the private sector we also have environmental policies formulated by the International Organization for Standardization and World Trade Organization, as main instruments of environmental policies. It is up to these instrument the conduct and compliance with economic strategies and conservation of environmental resources. We conclude that from the standpoint of legislation the principles, strategies and instruments needed for an efficient environmental management are already available, but require improvement, mainly in connection with a public management more effective in their applications and inspections in accordance with the rules and current legislation.

KEYWORDS: Environmental Management, Sustainability, Environmental Public Policies, Environment.

\section{INSTRUMENTOS DE POLÍTICAS PÚBLICAS EN GESTIÓN AMBIENTAL Y SOSTENIBILIDAD EN BRASIL}

\section{RESUMEN}

Este trabajo representa una síntesis sobre los instrumentos de las políticas públicas en Gestión Ambiental y Sostenibilidad en Brasil. Los objetivos embasan en la identificación, descripción, análisis y evaluación crítica de los principales instrumentos de las políticas públicas vigentes, precedida por una breve historia sobre la evolución de los mismos. En términos metodológicos fueron levantados los datos bibliográficos pertinentes a los históricos, órganos, legislación, instrumentos y estrategias aplicadas en las políticas públicas, con énfasis en aspectos relacionados con la Política Nacional de Medio Ambiente. Referencialmente estas políticas siguen las normas de la Constitución de la República Federativa del Brasil en 1988 y el Ministerio de Medio Ambiente, que agregan el Sistema Nacional de Medio Ambiente y el Consejo Nacional del Medio Ambiente, además del Instituto Nacional de Medio Ambiente y Recursos Naturales Renovables y la Ley Federal № 6.938/81 que trata de la Política Nacional de Medio Ambiente. En el sector privado también tenemos políticas ambientales formuladas por la Organización Internacional de Normalización y por la Organización Mundial del Comercio, como principales instrumentos de estas políticas ambientales. Es de estos instrumentos la gestión y el cumplimiento de las estrategias económicas y la conservación de los recursos ambientales. Concluimos que desde el punto de vista de la legislación los principios, las estrategias y los instrumentos necesarios para una gestión ambiental eficiente ya están disponibles, sin embargo, es necesario tener una mejora, especialmente en relación con una gestión pública más eficaz en sus aplicaciones y controles de acuerdo con las reglas y las leyes en vigor.

PALABRAS ClAVE: Gestión Ambiental, Sostenibilidad, Políticas Públicas Ambientales, Medio Ambiente.

\section{INTRODUÇÃO}

O conceito de políticas públicas, em pleno estado de direito democrático, deve necessariamente representar ou expressar a maneira como a sociedade deseja resolver os problemas e as adversidades que vão surgindo, e as políticas públicas ambientais não fogem a regra, entendendo-se que o processo político origina-se a partir de um movimento reivindicatório da sociedade em relação a um problema ou conflito, conforme Costa et al. (2002).

As políticas de gestão ambiental são caracterizadas em relação ao seu caráter e ao nível de abrangência, o que significa dizer que em relação ao caráter elas podem ser classificadas em públicas e privadas e quanto à abrangência, podem ser de políticas 
internacionais, federais, estaduais ou municipais, segundo Kraemer (2012). Considerando-se o conceito de gestão pública ambiental, podemos afirmar que as políticas públicas de gestão ambiental devem priorizar toda a gestão de recursos que protejam o ambiente natural, porém, fundamentalmente deve ser orientadoras na resolução de conflitos sociais ambientais, visando principalmente o bem estar social e a conservação de recursos naturais para as futuras gerações.

As políticas internacionais de gestão ambiental têm suas origens por ocasião dos grandes eventos envolvendo grande parte dos países do mundo, tal como a Conferência das Nações Unidas sobre Ambiente e Desenvolvimento, a Rio-92, promovida pela ONU, onde se emitiu um dos mais importantes documentos que foi a Agenda 21 (1992), contendo as principais políticas ambientais e de desenvolvimento em nível internacional, assim como a Declaração do Rio sobre Ambiente e Desenvolvimento, contendo os princípios para a preservação da integridade dos diversos sistemas ambientais mundiais, proporcionando um desenvolvimento humano com sustentabilidade.

Em relação aos aspectos privados das políticas de preservação ambientais globais, deve-se levar em consideração principalmente, as políticas ambientais formuladas pela Organização Internacional para Padronização (International Organization for Standardization) e pela Organização Mundial de Comércio (OMC); a primeira contendo as normas internacionais ISO da série 14000 - NBR ISO 14001 (1996, 2004), orientando as empresas na criação de sistemas de gestão ambiental no mundo, e a OMC colaborando por meio de restrições comerciais quando houver problemas relativos às questões ambientais. Isso confirma que procedimentos referenciados com ferramentas pertinentes a ISO e a OMC exercem papéis fundamentais na formulação de políticas ambientais, favorecendo as organizações cumpridoras dos princípios e normas ambientais em contratos de comércio internacional (produtos ambientalmente corretos) e, por outro lado, excluindo do comércio internacional as empresas que descumprem suas políticas ambientais.

\section{OBJETIVOS E METODOLOGIA}

Os objetivos deste trabalho embasaram-se primordialmente na identificação, descrição, análise e avaliação crítica sobre os principais instrumentos de políticas 
públicas em Gestão Ambiental e Sustentabilidade no Brasil, precedidos por um breve histórico sobre o desenvolvimento das mesmas no contexto atual.

Para a efetivação destes objetivos, em termos metodológicos foram levantados dados bibliográficos referentes ao histórico, órgãos, legislações, instrumentos e estratégias aplicadas em termos de políticas públicas em Gestão Ambiental e Sustentabilidade, ao longo do tempo no Brasil, com ênfase aos aspectos relacionados à Política Nacional do Meio Ambiente (PNMA). Ao final da análise e discussão sobre os principais instrumentos de políticas públicas em Gestão Ambiental vigentes, procurou-se elaborar algumas considerações pontuais que venham contribuir para um avanço nestas questões de grande relevância para um eficiente planejamento e desenvolvimento do país.

\section{HISTÓRICO SOBRE AS POLÍTICAS PÚBLICAS NO BRASIL}

Em termos de políticas públicas no Brasil temos a estrutura do Sistema Nacional do Meio Ambiente - SISNAMA (MMA, 1981), que é conduzida por um órgão superior governamental, o Conselho de Governo, cujas funções consistem em assessorar a Presidência da República nas formulações da política nacional e diretrizes governamentais ambientais para o país. Conforme o Ministério do Meio Ambiente (MMA, 1981), o SISNAMA possui um órgão consultivo e deliberativo denominado de CONAMA - Conselho Nacional do Meio Ambiente $(1986,1997)$, sendo o órgão executivo representado pelo IBAMA - Instituto Nacional do Meio Ambiente e dos Recursos Naturais Renováveis (IBAMA, 1995).

As políticas públicas de gestão e sustentabilidade ambiental no Brasil seguem primeiramente as normativas da Constituição da República Federativa do Brasil (1988), que fixam as diretrizes para o desenvolvimento das políticas ambientais públicas federais em seu Capítulo VI, Artigo 225. Estabelecem ainda além deste artigo, outras diretrizes complementares para questões ambientais nos Artigos $5^{\circ}$, 23, 24, 129, 170, 174, 187, 186 e 220.

No Brasil, toda a Política Nacional de Meio Ambiente, cujas funções e atribuições em relação ao poder público do poder público na condução e execução subordinam-se ao Decreto $n^{\circ} 99.274$ de 06/06/1990, que regulamenta a Lei $n^{\circ} 6.902$ de 27/04/1981 e a Lei $n^{\circ} 6.938$ de $31 / 08 / 1981$, onde vamos encontrar respectivamente normativas 
sobre a Criação de Estações Ecológicas e Áreas de Proteção Ambiental e sobre a Política Nacional do Meio Ambiente.

Neste processo da formulação e condução das políticas públicas ocorre ainda uma estreita parceria com o Ministério do Meio Ambiente e da Amazônia Legal, que atua enquanto coordenador da Política Nacional de Meio Ambiente (Lei Federal $\mathrm{n}^{\circ}$ 6938/81).

Em nível de Estados, as políticas públicas são coordenadas e conduzidas pelas Secretarias de Estado de Meio Ambiente, enquanto os Conselhos Estaduais de Meio Ambiente representam os órgãos consultivos e deliberativos, conforme a Constituição Federal (1988). Por outro lado, os órgãos executivos geralmente são criados como fundações ou empresas públicas que prestam serviços à administração direta, como no caso da Companhia Ambiental do Estado de São Paulo - CETESB, no Estado de São Paulo, ou como em alguns outros alguns Estados onde o órgão executivo corresponde a algum departamento ligado à Secretaria Estadual de Meio Ambiente (PMRP, 2008). Entretanto, em nível municipal na maioria dos municípios ainda carecem de uma secretaria municipal que seja responsável pela coordenação das políticas públicas municipais ambientais, assim como de um conselho de meio ambiente exercendo funções consultivas e deliberativas, e por fim de um órgão executivo, funções estas que, muitas vezes vem exercido pelo mesmo órgão estadual, por meio de convênios firmados entre as prefeituras e os estados.

Especificamente sobre a gestão de recursos hídricos, para o qual os olhos da humanidade se voltam frente a sua possível escassez, considera-se de acordo com a Lei 9.433/97, que a unidade administrativa territorial corresponde à bacia hidrográfica. Efetivamente, esta divisão é feita em termos de grandes bacias hidrográficas nacionais, e estas, por estado, que por sua vez subdividem-se em subbacias que ainda são divididas e administradas por microbacias. Muller (1997) destaca que este tipo de gerenciamento de ecossistemas é mais recente e corresponde a uma tendência em relação às políticas de proteção do ambiente natural, devido as suas peculiaridades próprias do ambiente natural.

Uma das mais recentes discussões sobre as questões ambientais ocorreu por ocasião do debate em torno do Novo Código Florestal, que foi aprovado de acordo com a Lei $12.651 / 2012$ de $25 / 05 / 2012$, embora com toda a polêmica e discussão 
não podemos dizer que houve avanços significativos. Isto seria apenas válido se considerarmos que o código anterior datava do ano de 1965 (Lei no 4771/1965) e que dormitou no Congresso por cerca de doze anos.

A consolidação das políticas de gestão ambiental, atualmente converge concentrando-se mais pontualmente sobre elementos naturais mais específicos, as quais a sociedade mais valoriza pela sua importância, tais como a biodiversidade, unidades de conservação, recursos hídricos, solos, paisagens excepcionais, os sítios fósseis; etc. Da mesma forma a fiscalização, o controle e estabelecimento de políticas de gestão ocorrem principalmente para determinados setores ou atividades preferenciais, tais como as atividades antrópicas, os processos e produtos da sociedade, seus produtos e rejeitos, sua influência na qualidade de vida, assim como em relação ao ambiente natural (CARVALHO et al, 2005).

Normalmente, os organismos financeiros internacionais, possuem uma grande força de pressão por meio de seu poder econômico, usando-as para impor o cumprimento das leis, princípios e normativas ambientais internacionais (certidões ambientais), por ocasião da análise de projetos de desenvolvimento financiados pelos mesmos. O Brasil sempre esteve subordinado às influências e exigências do Banco Mundial, quando da submissão de seus projetos de desenvolvimento em busca de financiamentos, sendo este fator altamente decisivo para a formação e evolução da Política Nacional de Meio Ambiente, segundo Souza (2001).

Após a Conferência da ONU sobre Ambiente Humano que ocorreu em Estocolmo Suécia (1972) houve uma grande repercussão no seio da sociedade brasileira, que na época vivia o ilusório milagre brasileiro, quando diversos pesquisadores de universidades e instituições de pesquisas iniciaram estudos objetivando desenvolverem novas tecnologias pertinentes ao meio ambientai, sobretudo com a preocupação formativa e de capacitação de recursos humanos. Em consequência dos interesses do meio acadêmico científico, provenientes da reunião de Estocolmo em 1972, envidaram-se os primeiros esforços para a criação de diversos cursos de pós-graduação em Ecologia do país (UFRGS, UFAM, UnB, Unicamp, UFSCAr) assim como a criação de disciplinas correlatas (Ciências Ambientais, Saneamento Básico e Saneamento Ambiental) em diversos cursos na área de Engenharia (1977/78). Corroborando o incremento de ações em políticas públicas ambientais no país, o movimento fortalece-se na década de 80 , levando a discussão e inclusão do 
Capítulo VI, inteiramente dedicada ao Meio Ambiente, na Constituição da República Federativa do Brasil (1988), cuja consagração final foi consolidada pela opção da ONU em realizar a ECO-92 no Rio de Janeiro - Brasil, como resultado da mobilização social no tocante aos temas associados ao meio ambiente.

\section{INSTRUMENTOS DE POLÍTICAS PÚBLICAS E A POLÍTICA NACIONAL DO MEIO AMBIENTE (PNMA)}

Cabe aos instrumentos de políticas públicas ambientais a finalidade precípua de conduzir o cumprimento das estratégias econômicas e preservação dos recursos ambientais. A Lei № 6.938/81, que dispõe sobre a Política Nacional do Meio Ambiente, em seu Artigo $2^{\circ}$, e suas disposições e modificações posteriores, contextualizam que os instrumentos da PNMA são:

I - o estabelecimento de padrões de qualidade ambiental;

II - o zoneamento ambiental; (Regulamento)

III - a avaliação de impactos ambientais;

IV - o licenciamento e a revisão de atividades efetiva ou potencialmente poluidoras;

V - os incentivos à produção e instalação de equipamentos e a criação ou absorção de tecnologia, voltados para a melhoria da qualidade ambiental;

VI - a criação de espaços territoriais especialmente protegidos pelo Poder Público federal, estadual e municipal, tais como áreas de proteção ambiental, de relevante interesse ecológico e reservas extrativistas; (Redação dada pela Lei no 7.804, de 18.07.89);

VII - o sistema nacional de informações sobre o meio ambiente;

VIII - o Cadastro Técnico Federal de Atividades e Instrumento de Defesa Ambiental;

IX - as penalidades disciplinares ou compensatórias do não cumprimento das medidas necessárias à preservação ou correção da degradação ambiental.

X - a instituição do Relatório de Qualidade do Meio Ambiente, a ser divulgado anualmente pelo Instituto Brasileiro do Meio Ambiente e Recursos Naturais Renováveis - IBAMA; Inciso incluído pela Lei no 7.804, de 18.07.89;

$X I$ - a garantia da prestação de informações relativas ao Meio Ambiente, obrigandose o Poder Público a produzí-las, quando inexistentes; Inciso incluído pela Lei no 7.804, de 18.07.89; 
XII - o Cadastro Técnico Federal de atividades potencialmente poluidoras e/ou utilizadoras dos recursos ambientais. Inciso incluído pela Lei no 7.804, de 18.07.89.

Somando-se aos instrumentos de políticas públicas anteriores, em relação à política pública ambiental brasileira, citados por Barbieri (1997a, 1997b); Silva Filho (1999), conforme constam na Tabela 01 , que as complementam, pois aí incluem os principais meios de controle por parte do poder público, das atividades que provocam grandes impactos ao meio ambiente e que são estabelecidas em documentos normativos em seus diferentes níveis.

Tabela 01- Principais instrumentos da Política Ambiental Pública do Brasil

\begin{tabular}{ll}
\hline GÊNERO & ESPÉCIE \\
\hline Comando e & - Padrão de emissão, \\
Controle & - Padrão de desempenho, \\
& - Proibições/restrições sobre produção, comercialização e uso de produtos, \\
& - Licenciamento Ambiental. \\
\hline & - Tributação sobre poluição, \\
Econômico & - Tributação sobre uso de recursos naturais, \\
& - Incentivos fiscais, \\
& - Criação e sustentação de mercados, \\
& - Financiamentos em condições especiais. \\
\hline \multirow{3}{*}{ Diversos } & - Educação Ambiental, \\
& - Reservas ecológicas e outras áreas de proteção ambiental, \\
& - Informações ao público, \\
& - Mecanismos administrativos e jurídicos de defesa do meio ambiente. \\
\hline & Fonte: Barbieri (1997a; 1997b) e Silva Filho (1999) adaptado
\end{tabular}

Alguns destes instrumentais são partes integrantes de outros em cadeia, como o licenciamento que exige o Estudo de Impacto Ambiental e o Relatório de Impacto Ambiental (EIA/RIMA), da qual a Avaliação de Impacto Ambiental (AIA) faz parte.

De acordo com Barreto (2001), no Brasil a política e legislação ambiental estão centradas em instrumentos de gestão ambiental como "o estabelecimento de padrões de qualidade ambiental, o zoneamento ambiental, a criação de espaços territoriais protegidos, a avaliação ambiental de empreendimentos considerados potencialmente poluidores, o licenciamento ambiental desses empreendimentos, a participação pública, o incentivo ao desenvolvimento tecnológico, o sistema de informações ambientais, o acesso público a essas informações, entre outros”. 
Podemos dizer que a Política Nacional do Meio Ambiente (PNMA), utiliza-se de cinco instrumentos principais que são amparados por ferramentas, sistemas e metodologias, que de acordo com Silva Filho (1999) são:

a)- Licenciamento: baseado na Avaliação de Impacto Ambiental (AIA), Estudo de Impacto Ambiental (EIA), Relatório de Impacto Ambiental (RIMA), Plano de Controle Ambiental (PCA), Plano de Recuperação de Áreas Degradadas (PRAD), Relatório de Avaliação Ambiental (RAA), Relatório de Controle Ambiental (RCA), Analise de Risco (AR), Estudo de Viabilidade Ambiental (EVA), Projeto Básico Ambiental (PBA), Termo de Referência (TR), Audiência Pública (AP), estabelecimento de padrões de qualidade ambiental e no sistema de informações e cadastro técnico ambiental federal;

b)- Incentivos econômicos: Fundo Nacional do Meio Ambiente (FNMA), Banco Nacional de Desenvolvimento Econômico e Social (BNDES);

c)- Inibições econômicas: Impostos ecológicos (ICM,Taxa de Reposição Florestal, etc.);

d)- Punição: Lei dos Crimes Ambientais, Código Florestal, etc.;

e)- Conservação: Sistema Nacional de Unidades de Conservação (SNUC), Corredores Ecológicos, Programa Piloto para a Proteção das Florestas Tropicais do Brasil (PPG7), restrição ao uso privado de recursos naturais (impostas pela Lei 4771/65), recuperação ambiental, auto suprimento e reposição florestal.

De acordo com Soares (2001) os instrumentos de gestão ambiental, são embasados em quatro tipos básicos de estratégias que conduzem a políticas públicas ambientais eficientes, quais sejam:

a)- Estratégias de Comando e controle: constituem-se num conjunto de regulamentos e normas governamentais, objetivando influenciar de forma direta as atitudes do elemento impactante, apontando padrões e formas de controle dos impactos.

b)- Estratégias Econômicas: objetiva beneficiar o agente impactante que reduz os impactos, ou punir quem ocasiona impactos negativos.

c)- Estratégias de Autorregulação: baseada na gestão ambiental sob a tutela do próprio agente impactante e controle pelas forças de mercado. 
d)- Estratégias de Macropolíticas com interface ambiental: estratégias de desenvolvimento tecnológico, planejamento energético, planejamento regional e urbano, educação ambiental, etc.

Devemos considerar que as estratégias, princípios, instrumentos e métodos essenciais para uma eficiente gestão ambiental praticamente já se encontram implantadas, necessitando apenas de melhor aprimoramento e desenvolvimento, principalmente quanto ao gestor público e nas aplicações e fiscalizações da legislação vigente.

A Gestão e Sustentabilidade Ambiental no Brasil representa um dos pilares do Direito Ambiental, cujas premissas expressam-se no caput do art. 225 da Constituição Federal como direito fundamental do homem (Art. 225, CF), onde se preconiza que "todos têm direito ao meio ambiente ecologicamente equilibrado, bem de uso comum do povo e essencial à sadia qualidade de vida, impondo-se ao poder público e à coletividade o dever de defendê-lo e preservá-lo para os presentes e futuras gerações" (BRASIL, 2004). Por outro lado, a Ordem Econômica e Financeira do país, insere-se no Título VII da CF-88, em conjunto com o Capítulo I que trata dos Princípios Gerais da Atividade Econômica. Dispõe o Art. 170 do referido diploma legal que: "A ordem econômica, fundada na valorização do trabalho humano e na livre iniciativa, tem por fim assegurar a todos existência digna, conforme os ditames da justiça social, observados os seguintes princípios: (...)" (BRASIL, 2004).

Como a Constituição Brasileira determina que a gestão ambiental subordinase a responsabilidade conjunta da União, dos Estados e dos Municípios (art. 225), deve-se também proceder a uma análise mais minuciosa em relação ao art. 170, onde se dispõe sobre a ordem econômica, observando-se a intervenção do Estado em atividades econômicas que gerem impactos ambientais. Veja que encontramos aqui dois princípios aparentemente conflitantes, ou seja, o artigo $3^{\circ}$ através do Inciso II, que prevê garantias ao desenvolvimento nacional e ao mesmo tempo em que o artigo 225 assegura uma proteção ambiental nos termos da lei. Nestes termos, o desenvolvimento representa o crescimento econômico, a desregulamentação e a diminuição do papel do Estado e o desenvolvimento globalizado como direito fundamental da sociedade. 


\section{Periódica Eletrânica \\ Fórum Ambiental}

da Alta Paulista
Volume 11, Número 07, 2015

Politicas Públicas e a Proteção do Meio Ambiente

\section{CONSIDERAÇÕES FINAIS}

Os instrumentos referenciais de políticas públicas de Gestão e Sustentabilidade Ambiental no Brasil seguem fundamentalmente as normativas da Constituição da República Federativa do Brasil de 1988, que fixam as diretrizes para o desenvolvimento das políticas ambientais públicas federais em seu Capítulo VI, Artigo 225.

Dentro deste contexto, em termos de órgãos executivos destas políticas públicas temos o Ministério do Meio Ambiente - MMA, cujo Sistema Nacional do Meio Ambiente - SISNAMA e seu Conselho Nacional do Meio Ambiente - CONAMA, somam-se ao Instituto Nacional do Meio Ambiente e dos Recursos Naturais Renováveis - IBAMA.

No tocante aos aspectos privados das políticas globais de preservação ambiental, devemos considerar também as políticas ambientais formuladas pela Organização Internacional para Padronização - ISO orientando as empresas na criação de sistemas de gestão ambiental e a Organização Mundial de Comércio OMC colaborando por meio de restrições comerciais quando houver problemas relativos às questões ambientais.

O processo de consolidação das políticas de Gestão Ambiental e Sustentabilidade atualmente concentram-se de forma mais pontual sobre questões as quais a sociedade mais valoriza como a biodiversidade, unidades de conservações, recursos hídricos, solos, paisagens excepcionais, os sítios fósseis; etc. Desta forma a fiscalização, o controle e estabelecimento de políticas de gestão convergem principalmente para determinados setores ou atividades como as ações antrópicas, os processos, produtos e rejeitos da sociedade e suas influências na qualidade de vida.

A Lei Federal ํㅜ 6.938/81, que dispõe sobre a Política Nacional do Meio Ambiente - PNMA (Artigo $2^{\circ}$ ) contextualizam que os instrumentos de Políticas Públicas de Gestão e Sustentabilidade Ambiental no Brasil devem utilizar-se dos instrumentais e ferramentas, sistemas e metodologias respaldados pelo licenciamento, incentivos econômicos, inibições econômicas, punição e conservação. 
Enfim, ressaltamos que cabe a estes instrumentos de políticas públicas ambientais, entre outros, a finalidade na condução e cumprimento das estratégias econômicas e preservação dos recursos ambientais; mesmo ressalvando-se que as estratégias, princípios, instrumentos e métodos essenciais para uma eficiente gestão ambiental praticamente já se encontram implantadas, necessitando apenas de aprimoramento e desenvolvimento, principalmente quanto ao gestor público e nas aplicações e fiscalizações efetivas das legislações vigentes.

\section{REFERÊNCIAS}

ABNT - ABNT. NBR ISO 14001: Sistemas de Gestão Ambiental - Especificação e Diretrizes para Uso. Rio de Janeiro: ASSOCIAÇÃO BRASILEIRA DE NORMAS TÉCNICAS - ABNT, 1996.

ABNT - ASSOCIAÇÃO BRASILEIRA DE NORMAS TÉCNICAS - NBR ISO 14001 - Sistemas de gestão ambiental - Requisitos com a orientação para uso. Rio de Janeiro, 2004.

AGENDA 21 - Cúpula da Terra: Conferência das Nações Unidas sobre o Meio Ambiente e Desenvolvimento. Rio de Janeiro, Centro de Informações das Nações Unidas, 1992.

BARBIERI, J. C. Políticas públicas indutoras de inovações tecnológicas ambientalmente saudáveis. Rio de Janeiro, Revista de Administração Pública. v. 31, n. 2, p.135-52. 1997a.

BARBIERI, José Carlos. Desenvolvimento e Meio Ambiente: as estratégias de mudanças da Agenda 21 - Ed. Vozes, 6‥ed. Petrópolis, RJ. 1997b.

BARRETO, Maria Laura. Mineração e desenvolvimento sustentável: Desafios para o Brasil. Rio de Janeiro: CETEM/MCT, 2001.

BRASIL. Constituição Federal de 1988 (Constituição Federal, Ato das Disposições Constitucionais Transitórias, Emendas Constitucionais de Revisão e Emendas Constitucionais). Brasília: Senado Federal, Secretaria-Geral da Mesa, 2001.

BRASIL. Constituição da República Federativa do Brasil. 9. ed. rev., atual. e ampl., São Paulo: Revista dos Tribunais, 2004.

BRASIL. Lei ํํ 4.771, de 15 de Setembro de 1965. Código Florestal. Institui o novo Código Florestal.

BRASIL. Lei $\mathbf{N}^{\circ}$ 6.902, de 27 de Abril de 1981. Dispõe sobre a criação de Estações Ecológicas, Áreas de Proteção Ambiental e dá outras providências. 1981.

BRASIL. Lei № 6.938, de 31 de Agosto de 1981. Dispõe sobre a Política Nacional do Meio Ambiente, seus fins e mecanismos de formulação e aplicação, e dá outras providências. 1981.

BRASIL. Lei № 7.804, de 18 de Julho de 1989. Altera a Lei oㅜ 6.938, de 31 de agosto de 1981, que dispõe sobre a Política Nacional do Meio Ambiente, seus fins e mecanismos de formulação e aplicação, e dá outras providências.

BRASIL. Lei № 9.433, de 8 de Janeiro de 1997. Institui a Política Nacional de Recursos Hídricos, cria o Sistema Nacional de Gerenciamento de Recursos Hídricos, e da outras providências. 1997.

BRASIL. DECRETO N 99.274, de 6 de Junho de 1990. Regulamenta a Lei ํㅜ 6.902, de 27 de abril de 1981, e a Lei no 6.938, de 31 de agosto de 1981. 1990. 
BRASIL. Lei № 12.651, de 25 de Maio de 2012. Dispõe sobre a proteção da vegetação nativa; e dá outras providências. 2012.

CARVALHO, P. G. M.; OLIVEIRA, S. M. M. C.; BARCELLOS, F. C., ASSIS, J. M. Gestão Local e Meio Ambiente. Ambiente \& Sociedade - v. 8, n. 1, 2005.

CONAMA - Conselho Nacional do Meio Ambiente. Resolução no 001, de 23 de janeiro de 1986, publicado no D. O U. de 17.2.86. Disponível em:

<www.mma.gov.br/por/conama/res/res/86/res0186.html> Acesso em 23 out. 2014.

CONAMA. Conselho Nacional do Meio Ambiente. Resolução no 237, de 19 de Dezembro de 1997, Dispõe sobre a revisão e complementação dos procedimentos e critérios utilizados para 0 licenciamento ambiental. Disponível em:

<http://www.mma.gov.br/port/conama/res/res97/res23797.html> Acesso em 23 out. 2014.

COSTA, Heloisa S. de M.; OLIVEIRA, Alexandre M. de; RAMOS, Marcelo V. População, Turismo e Urbanização: conflitos de uso e gestão ambiental. Ouro Preto: XIII Encontro da Associação Brasileira de Estudos Populacionais. 2002.

IBAMA. Anais do Seminário sobre a Formação do Educador para atuar no Processo de Gestão Ambiental. Brasília: Instituto Brasileiro do Meio Ambiente e dos Recursos Naturais Renováveis, Série Meio Ambiente em Debate $n^{\circ} 1,1995.29 p$.

KRAEMER, Maria Elisabeth. Gestão ambiental: Um enfoque no desenvolvimento sustentável. 2012. Disponível em:

http://www.gestaoambiental.com.br/recebidos/maria kraemer pdf/GEST\%C3O\%20AMBIENTAL\%20 UM\%20ENFOQUE\%20NO\%20DESENVOLVIMENTO\%20SUSTENT\%C1VEL.pdf. Acesso em 23 de out. de 2014.

MMA - Ministério do Meio Ambiente. Lei no 6.938/81. SISNAMA: Sistema Nacional do Meio Ambiente.1981. Disponível em:

$<$ http://www.mma.gov.br/governanca-ambiental/sistema-nacional-do-meio-ambiente $>$ Acesso em 17 de Nov. de 2014

MMA Ministério do Meio Ambiente. Lei no 6.938/81. SISNAMA: Sistema Nacional do Meio Ambiente.1981. Disponível em:

$<$ http://www.mma.gov.br/governanca-ambiental/sistema-nacional-do-meio-ambiente $>$ Acesso em 17 de Nov. de 2014

PMRP. Projeto de Lei no 895/98. Cria o Programa Agenda 21 no âmbito de Ribeirão Preto/SP e dá outras providências. 1998. Disponível em:

http://www.ribeiraopreto.sp.gov.br/J321/pesquisa.xhtml?lei=3829 Acesso em 17 de nov. 2014.

SILVA FILHO, José Carlos L. da. Sistema de gestão ambiental aplicado a prefeituras: uma nova possibilidade de gestão pública. Porto Alegre: UFRGS, Mestrado em Gestão da Tecnologia e da Produção, 1999.

SOARES, Sebastião R. Estratégias de política ambiental - ENS 5139 - Economia, direito e administração ambiental. Florianópolis: UFSC - Engenharia Sanitária e Ambiental, 2001.

SOUZA, M. R. A Implantação do Sistema de Gestão Ambiental Segundo ISO 14001 Dissertação de Mestrado do programa da Escola Federal de Engenharia de Itajubá. 2001. 